\title{
Barriers in Utilization of Reproductive and Child Health Services in Slums of Delhi, India: an Observational Study
}

\author{
Dr. Anand Kumar Verma ${ }^{1}$, Dr. Prakash Ranjan ${ }^{2}$, Dr. Rabi Bhushan ${ }^{3 *}$, Dr. V. K. Tiwari ${ }^{4}$
}

${ }^{1}$ Department of Community Medicine, Saraswati Medical College, Lucknow, UP, India

${ }^{2}$ Department of Epidemiology, The National Institute of Health and Family Welfare, New Delhi, India

${ }^{3}$ Department of Community Medicine, SNM Medical College, Dhanbad, Jharkhand, India

${ }^{4}$ Head, Department of Planning \& Evaluation, The National Institute of Health and Family Welfare, New Delhi, India

DOI: $10.36347 /$ sjams.2020.v08i11.012

| Received: 30.10.2020 | Accepted: 09.11.2020 | Published: 13.11.2020

*Corresponding author: Dr. Rabi Bhushan

Abstract

Background: The utilization of Reproductive and Child health $(\mathrm{RCH})$ services is often influenced by the sociocultural, financial, access, political barriers acting at the community, family and individual level. Aim and objective: To examine the barriers in utilization of RCH services in slums. Material \& Methods: The study was carried out in three slums of Delhi with a well representative sample of 421 women, who delivered the child within 6 months. Quantitative and qualitative study design was followed to collect the data. Results: The supply side barriers such as physical access and facilities were faced by the service providers. The demand side barriers such as socio-cultural, financial and access barriers were faced by the service receivers in order to avail the services. Conclusions and Recommendation: In order to overcome the barriers faced by the women of slums, it is important to improve the access to services so that they get them easily. Some of the imperative actions such as strengthening community mobilization through inter-personal communication, dialogue with the key influencers in the community as well as continuous engagement with and sensitization of the service providers.

Keywords: RCH; Slums; Barriers; Socio-Cultural.

Copyright $(\odot 2020$ The Author(s): This is an open-access article distributed under the terms of the Creative Commons Attribution 4.0 International License (CC BY-NC 4.0) which permits unrestricted use, distribution, and reproduction in any medium for non-commercial use provided the original author and source are credited.

\section{INTRODUCTION}

Reproductive and Child Health (RCH) program is a comprehensive sector wide flagship program under the umbrella of the Government of India's (GOI) National Health Mission (NHM) to deliver the $\mathrm{RCH}$ targets for reduction of maternal and infant mortality and total fertility rates [1]. Government of India during 1997-98 launched the RCH Program for implementation by integrating Child Survival and Safe Motherhood (CSSM) Program with other Reproductive and Child Health $(\mathrm{RCH})$ services. The Government of India launched the NRHM, in April 2005 which sought to provide accessible, affordable and quality health care to the rural population, especially the vulnerable sections [2]. During NRHM, vulnerable population and poor residing in urban areas were left out. The Union Cabinet on $1^{\text {st }}$ May 2013 has approved the launch of National Urban Health Mission (NUHM) to improve the health status of the urban population particularly slum dwellers and other vulnerable sections by facilitating their access to quality primary health care. NUHM seeks to improve the health status of the urban population particularly urban poor and other vulnerable sections by facilitating their access to quality primary healthcare. NUHM covers all State capitals, district headquarters and other cities/ towns with a population of 50,000 and above (as per census 2011) in a phased manner. Cities and towns with population below 50,000 will continue to be covered under NRHM.

\section{Selected RCH services}

Antenatal care is the systemic supervision of women during pregnancy to monitor the progress of fetal growth and to ascertain the well-being of the mother and the fetus. ANC session should include Registration (within 12 weeks), Physical examination, weight, Blood Pressure, abdominal examination, Identification and referral for danger signs. Ensuring consumption of at least 100 IFA tablets (for all pregnant women) and 200 IFA tablets (for anemic women). Essential lab investigations which includes $\mathrm{Hb} \%$, urine for albumin / sugar and pregnancy test. T.T immunization (two doses at interval of one month), counseling on nutrition, birth preparedness, safe abortion and institutional delivery and referral linkages for complicated pregnancies and deliveries. 
Intranatal Care includes normal delivery with use of partograph, active management of third stage of labor, infection prevention, identification and referral for danger signs pre-referral management for obstetric emergencies e.g. Eclampsia, PPH, Shock Assured referral linkages with higher facilities. Essential newborn care includes neonatal resuscitation, warmth, infection prevention, and initiation of breastfeeding within an hour of delivery.

Postnatal Care includes minimum 6 hrs. stay, post-delivery counseling for feeding, nutrition, family Planning, hygiene, immunization and postnatal checkup, home visits on 3rd, 7th and 42nd days both for mother and baby are needed. Additional visits are needed for the newborn on day 14, 21 and 28. Further visits may be necessary for LBW and sick newborns for timely identification of danger signs and complications, referral of mother and baby. Newborn care also include warmth, hygiene and cord care, exclusive breastfeeding for 6 months, and identification, management and referral of sick neonates, low birth weight (LBW) and pre-term newborns. Referral linkages for management of complications includes care of LBW newborns 1800 $\mathrm{gm}$ and less, referral services for newborns of birth defects and screening for congenital anomalies [3].

\section{Barriers in RCH Utilization}

Supply side barriers include the service providers in the difficult to reach areas face access and language barriers. In addition, the shortage of staff to attend the critical cases and proper training on the new maternity services that made them all the more difficult to provide services to the women living in the slum.

Demand side barriers including cost of transportation and bad roads to the health facility. These were pointed out as the major barriers to accessibility, about $50 \%$ women in slum areas stated that cost of transportation is the key barrier faced by most women respondents for the ANC checkup and delivery [4]. Utilization of health services is affected by a complex interrelationship of multiple factors that work synergistically at individual, community and societal levels. Factors that contribute to or act as a barrier to health utilization are Economic factors like poverty, income, access to food and shelter; Social factors like social status, gender discrimination, perceived power, self-esteem, social support, isolation; Environmental factors; Political factors; Access to services; Cultural factors like cultural and language barriers; Cost of services; Individual factors and Out-of-Pocket Expenditures.

One of the significant targets of Sustainable Development Goals (SDGs) is to improve the maternal and child health under goal 3 i.e. ensuring healthy lives and promoting wellbeing for all. In developing regions like sub-Saharan Africa and South Asia pregnancy and childbirth related deaths are comparatively higher than the developed countries. In these countries the risk of pregnancy-related issues and other health consequences after child birth is even higher. In order to ensure greater impact through the Reproductive Child Health $(\mathrm{RCH})$ program, it is important to understand the financial, socio-cultural, communication and political barriers in accessing these services. Nevertheless, the evidences from barrier studies on reproductive healthcare suggest that, demand as well as supply side barriers are important factors in deterring patients from accessing adequate services for reproductive healthcare. These barriers are likely to be more detrimental for the poor and other vulnerable groups, where the costs for accessing the services, lack of information and cultural barriers affect them from benefiting the free reproductive health care services provided by the government.

India has low awareness regarding government schemes, inappropriate household practices, negative social norms, and lack of access to basic health information and low self-efficacy which limits the impact of many Reproductive Maternal Newborn Child Health (RMNCH) programmes [5].

Under the NHM/ NRHM, both supply side and demand side interventions are implemented to improve access and utilization of RCH services by the urban and rural population. These interventions have contributed in improving utilization of $\mathrm{RCH}$ services. However, utilization of $\mathrm{RCH}$ services and adverse health outcomes among slum population remains a cause of concerns. This is evident from the available data which indicates lower utilization of services like ANC, institutional delivery and immunization services in slum population. Although enough amount of information is available on utilization of $\mathrm{RCH}$ services through various studies, yet detailed information on access, utilization, barriers and client satisfaction on $\mathrm{RCH}$ services by the underprivileged slum population is scanty. Therefore, it has been decided to undertake this study in Delhi.

\section{Aim AND OBJECTIVE}

To examine the demand and supply side barriers including perception of women regarding quality of services that limit the access to and utilization of selected RCH services in slums of Delhi.

\section{Methodology}

The present research work is descriptive and cross-sectional type of study done in three selected slums of Delhi. The study data was collected over a period of three months from October to December 2018 over a sample size of 421 women of slum having child of age from 0 to 6 months. The sample size was calculated as 381 considering a recent study by Devasenapathy et al., [6] where they found $46 \%$ women getting registered during first trimester. Considering $10 \%$ non-response, a total sample of 421 mothers were 
interviewed during data collection. Probability sample was used for selection of slums as this is the only sampling method that allows drawing valid conclusion about population. A Multi-stage random sampling design was used to select the mothers from selected slums in Delhi as this is the most feasible approach for large population. There are 11 Districts in Delhi, at the first stage, $25 \%$ (i.e. three) Districts were randomly selected for this study. In the second stage, from each selected District, list of slums published by Delhi Government was compiled and from the list one slum of approximately 5000 population was randomly selected from three selected districts. In the third stage, from each selected slum, list of households having recently delivered mother (within 6 month) was prepared. From that list, households were randomly selected for the interview of mothers regarding utilization of selected $\mathrm{RCH}$ services. Thus, the study covered 421 mothers from three different slums of Delhi by using inclusion criteria as mother who delivered the baby within six months and exclusion criteria as mothers who were severely ill. Primary data were collected using interview schedules developed for mothers. USAID tool 7 was first pre-tested in a different slum of Delhi based on the finding of pre-testing, tool was modified appropriately. Data collected from mothers were analyzed using descriptive and analytical techniques with the help of statistical software SPSS version 20. Appropriate statistical test like Chi-square was applied to show the association as per the objectives of the study.

\section{RESULTS}

\section{Socio Demographic Characteristics of Women Respondents}

The socio demographic characteristics includes 92\% mothers belonged to Hindu religion, $91 \%$ of residents belonged to schedule caste. Also, out of 421 mothers, $36 \%$ mothers were just literate, $27 \%$ were up to primary level, nearly one third $(33 \%)$ spouse were educated up to primary school, and almost same (34\%) were educated junior high school level. The finding of the study also shows that, among 421 mothers, 56\% were married before age of 20 years, and $39 \%$ were married between age of 20 to 25 years, $76 \%$ had 2 to 3 children and $18 \%$ had one child.

Utilization of RCH services

\begin{tabular}{|c|c|c|c|}
\hline Utilization of RCH services & Category of utilization & Frequency & Percent \\
\hline Confirmation of Pregnancy & $\begin{array}{l}\text { Did not test } \\
\text { With purchased kit } \\
\text { By private doctor } \\
\text { By government staffs } \\
\text { Total }\end{array}$ & $\begin{array}{l}4 \\
281 \\
5 \\
131 \\
421\end{array}$ & $\begin{array}{l}1 \\
66.7 \\
1.2 \\
31.1 \\
100\end{array}$ \\
\hline Place of ANC registration & $\begin{array}{l}\text { Not registered } \\
\text { Private hospital } \\
\text { Government hospital } \\
\text { Total }\end{array}$ & $\begin{array}{l}40 \\
32 \\
349 \\
421 \\
\end{array}$ & $\begin{array}{l}9.5 \\
7.6 \\
82.9 \\
100 \\
\end{array}$ \\
\hline Trimester of ANC registration & $\begin{array}{l}\text { No Registration } \\
\text { First trimester } \\
\text { Second trimester } \\
\text { Third trimester } \\
\text { Total }\end{array}$ & $\begin{array}{l}40 \\
126 \\
183 \\
72 \\
421 \\
\end{array}$ & $\begin{array}{l}9.50 \\
29.94 \\
43.46 \\
17.10 \\
100\end{array}$ \\
\hline Number of ANC & $\begin{array}{l}\text { No ANC done } \\
1 \text { time } \\
2 \text { to } 5 \text { times } \\
6 \text { to } 8 \text { times } \\
9 \text { to } 10 \text { times } \\
\text { Total }\end{array}$ & $\begin{array}{l}40 \\
44 \\
219 \\
91 \\
27 \\
421\end{array}$ & $\begin{array}{l}9.51 \\
10.45 \\
52.00 \\
21.62 \\
6.42 \\
100\end{array}$ \\
\hline Use of Iron and Folic Acid Tablet & $\begin{array}{l}\text { Yes } \\
\text { No } \\
\text { Total } \\
\end{array}$ & $\begin{array}{l}289 \\
132 \\
421 \\
\end{array}$ & $\begin{array}{l}68.6 \\
31.4 \\
100 \\
\end{array}$ \\
\hline T.T. inj. taken during pregnancy & $\begin{array}{l}\leq 1 \mathrm{~T} . \mathrm{T} . \\
2 \mathrm{~T} . \mathrm{T} . \\
\text { Total }\end{array}$ & $\begin{array}{l}41 \\
381 \\
421 \\
\end{array}$ & $\begin{array}{l}9.7 \\
90.3 \\
100 \\
\end{array}$ \\
\hline USG done during ANC & $\begin{array}{l}\text { No USG } \\
1 \text { USG } \\
2 \text { USG } \\
3 \text { USG } \\
\geq 4 \text { USG } \\
\text { Total }\end{array}$ & $\begin{array}{l}63 \\
154 \\
123 \\
76 \\
5 \\
421\end{array}$ & $\begin{array}{l}15 \\
36.6 \\
29.2 \\
18.1 \\
1.2 \\
100\end{array}$ \\
\hline
\end{tabular}




\begin{tabular}{|l|l|l|l|}
\hline \multirow{5}{*}{ Transport used during delivery } & Own vehicle & 4 & 1.1 \\
& Private vehicle & 269 & 76.9 \\
& Government vehicle & 77 & 22 \\
& Total & 350 & 100 \\
\hline \multirow{5}{*}{ Place of delivery } & At home by non-SBA & 5 & 1.2 \\
& At home by SBA & 66 & 15.7 \\
& Government hospital & 312 & 74.1 \\
& Private hospital & 38 & 9.0 \\
& Total & 421 & 100 \\
\hline \multirow{3}{*}{ Food during stay in hospital } & Yes & 302 & 86.3 \\
& No & 48 & 13.7 \\
& Total & 350 & 100 \\
\hline \multirow{3}{*}{ Scheduled vaccination completed } & Yes & 335 & 79.6 \\
& No & 46 & 20.4 \\
& Total & 421 & 100 \\
\hline
\end{tabular}

\begin{tabular}{|c|c|c|c|}
\hline \multicolumn{4}{|c|}{ Barriers of RCH services } \\
\hline Barriers & Category of barriers & Frequency & Percentage \\
\hline \multirow{5}{*}{ No use of ANC services } & Did not feel necessity & 160 & 55.2 \\
\hline & Distance from health facility & 27 & 9.3 \\
\hline & Lack of support from health worker & 19 & 6.5 \\
\hline & Lack of support from husband & & \\
\hline & Total & $\begin{array}{l}84 \\
290\end{array}$ & $\begin{array}{l}29 \\
100\end{array}$ \\
\hline \multirow{4}{*}{ No use of Iron Folic Acid Tablet } & Did not feel necessity & 86 & 65.2 \\
\hline & Did not get from hospital & 1 & 0.8 \\
\hline & Fear of side effect & 43 & 32.6 \\
\hline & Total & 132 & 100 \\
\hline \multirow{6}{*}{$\begin{array}{l}\text { Lack of Scheduled Vaccination of T.T. } \\
\text { Injection }\end{array}$} & Did not feel necessity & 27 & 65.9 \\
\hline & Did not get from hospital & 6 & 14.6 \\
\hline & Fear of injection & 4 & 9.8 \\
\hline & Lack of family cooperation & 1 & 2.4 \\
\hline & Domestic responsibility & 3 & 7.3 \\
\hline & Total & 41 & 100 \\
\hline \multirow{7}{*}{ No USG during ANC } & Did not feel necessity & 52 & 82.5 \\
\hline & Did not done from hospital & 4 & 6.4 \\
\hline & Money problem & 2 & 3.2 \\
\hline & Distance from hospital & 1 & 1.6 \\
\hline & Fear of test & 3 & 4.8 \\
\hline & Lack of family cooperation & 1 & 1.6 \\
\hline & Total & 63 & 100 \\
\hline \multirow{7}{*}{ Home Delivery } & Did not feel necessity & 54 & 76.1 \\
\hline & Distance from hospital & 1 & 1.4 \\
\hline & Lack of family cooperation & 7 & 9.9 \\
\hline & Lack of privacy & 1 & 1.4 \\
\hline & Social norms & 4 & 5.6 \\
\hline & Domestic responsibility & 4 & 5.6 \\
\hline & Total & 71 & 100 \\
\hline \multirow{4}{*}{$\begin{array}{l}\text { Lack of Scheduled immunization to } \\
\text { children }\end{array}$} & Did not feel necessity & 84 & 97.7 \\
\hline & Did not get from hospital & 1 & 1.2 \\
\hline & Lack of family cooperation & 1 & 1.2 \\
\hline & $\begin{array}{l}\text { Total } \\
\text { Highly satisfied }\end{array}$ & $\frac{86}{34}$ & $\frac{100}{97}$ \\
\hline \multirow{2}{*}{$\begin{array}{l}\text { Levels of satisfaction by mother during } \\
\text { institutional delivery }\end{array}$} & $\begin{array}{l}\text { Highly satisfied } \\
\text { Satisfied }\end{array}$ & $\begin{array}{l}34 \\
316\end{array}$ & $\begin{array}{l}9.7 \\
90.3\end{array}$ \\
\hline & Total & 350 & 100 \\
\hline
\end{tabular}

\section{DISCUSSION}

The present study finding reveals that out of 290 women who did not utilize ANC services, 55.2\% women feels that ANC is not necessary while $29 \%$ and $6.5 \%$ of the women said that they did not use the ANC services due to lack of support from husband and lack of support from health worker respectively. Similar 
study done by Uldbjerg C S et al., showed that the main perceived barriers to ANC utilization were identified as poor awareness among women, poor attitude of health workers, socio-cultural practices not being successfully aligned to ANC and lack of support from the husband, including difficulties in encouraging him to accompany to attend ANC [7].

Similar study done by Chimatiro C.S revealed that among several barriers ranging from cultural beliefs, social, economic to service delivery barriers, poor attitude of health workers was one of the prominent barrier. In the same study, most women pointed out that they started ANC late because some health workers were rude and do not observe confidentiality [8].

In the present study it was found that among pregnant women 17 percent used home delivery. Among them $76.1 \%$ feel that institutional delivery is not necessary for them while 9.9 percent of women told that they have opted for home delivery due to noncooperation from family members. So, poor sense of need was the major reason for home delivery among them. Similar cause of barrier of utilization of institutional delivery was also seen in a study done by Parika Pahwa et al., who found that, the major reason for not opting for an institutional delivery as stated by $53 \%$ of women was that, "they did not feel it necessary" while $20 \%$ blamed the non-cooperative family members [9]. Contrary to the findings of the present study, a study done by S Vaibhav et al., showed the main reason for not having institutional delivery was long waiting time in hospital and lack of proper facilities (50\%) followed by non-cooperative hospital staff $(36.2 \%)$ [10].

In the present study it was found that out of 421 women, $132(31.5 \%)$ women did not used Iron \& Folic acid during the period of pregnancy. Among mothers who were not getting IFA tablets, $65.2 \%$ told the reason as "Not knowing about importance of IFA tablets" and $32.6 \%$ told that the reason behind this was "The fear of side effects". As compared to this finding, A similar study done by Amanda Wendt et al., it was found that Overall, $62.6 \%$ of women did not received any IFA during their last pregnancy [11]. Another study done by Kendra Siekmans et al., shows that the main reason behind not using IFA tablets were- insufficient IFA supplies and inadequate counseling to encourage consumption and these two factors were the most common barriers to both coverage and adherence [12].

In the present study 20.4 percent of the women reported that they have not vaccinated their children according to the National Immunization Schedule. Out of them, $97.7 \%$ mothers gave reason as "did not feel necessity of vaccination for child" whereas $1.2 \%$ each reported the reason as non-availability at the nearest Government health centre and non-cooperation from family members. Regarding T.T. immunization for mothers, it was found in the present study that $10 \%$ of the mothers did not received recommended two doses of T.T. vaccine during their last pregnancy. The common reasons were- Did not feel necessity $(65.9 \%)$, unavailability at the health centre $(14.6 \%)$ and fear of injection $(9.8 \%)$ and lack of time due to other domestic responsibilities $(7.3 \%)$. In a Similar study done by KJ Awosan et al., revealed that less than a quarter of respondents $(23.6 \%)$ had received two or more doses of T.T. vaccine during their last pregnancy. The main barriers to utilization of vaccines were lack of awareness about the vaccine $(41.8 \%)$, not being aware of its benefits (36.7\%), and fear of injection $(21.5 \%)$ [13].

It was found in the present study that almost $15 \%$ of the mothers did not utilize the USG during their last pregnancy. This rate is much lesser than in most part of rural India. The common reasons were- did not feel necessity $(82.5 \%)$, unavailability at the health centre $(6.4 \%)$ and fear of the test $(4.8 \%)$. Among study participants of the present study, $83 \%$ of the women were satisfied with the overall services they received during child delivery by the health system. Among them, majority were highly satisfied $(90.3 \%)$ and $9.7 \%$ were moderately satisfied with health services during institutional delivery.

When we probed into the barriers of utilization of $\mathrm{RCH}$ services, it was revealed in the present study that lack of knowledge on benefits of maternal and child health services, cultural and traditional beliefs, trust in TBAs, lack of decision making power of women, previous negative experiences with health facilities, fear of going to an unfamiliar setting and lack of privacy were the main factors causing the non-utilization of $\mathrm{RCH}$ services. In addition, transport problems in inaccessible areas were the main contributing factor. Lack of logistic supplies and equipment, insufficient knowledge and skills and unprofessional behavior of health workers were the other key barriers in utilization of the RCH services. Further, it was found that Women who have had ANC visits during the index pregnancy were more likely to subsequently use skilled delivery attendants. Lack of time was also observed as a barrier in the present study which is very similar to the observation of a study conducted in Sudan where Women were found to be overwhelmed with domestic chores and had little or no time to attend ANC [14]. The lack of publicity and visibility of the $\mathrm{RCH}$ services to the receivers were also found to be a barrier in accessing the services.

The findings of the present study are similar with the findings of the study done by Tarekegn SM et $a l$., who found that the education of women, place of residence, ethnicity, parity, women's autonomy and household wealth had a significant association with the use of maternal health services. Utilization $\mathrm{RCH}$ 
services is more among more autonomous women than those spending is controlled by other family members [15].

\section{Conclusions}

The study identified the supply side barriers in utilization of RCH services which can help in identifying and suggesting the measures for improvement of the health care services especially the RCH services. The role of socio-cultural beliefs and practices in relation to pregnancy and the level of awareness about health during pregnancy were recognized as important in achieving effective $\mathrm{RCH}$ utilization.

\section{RECOMMENDATION}

In order to overcome the barriers faced by the women of slums, it is important to improve the access to services so that they get them easily. Some of the imperative actions such as strengthening community mobilization through inter-personal communication, dialogue with the key influencers in the community as well as continuous engagement with and sensitization of the service providers. Specific intervention program need to be planned and conducted to improve the maternal health practices and eventually improve the health status.

The potential limitations in this study were all information on ANC services received was based on recall which might have led to recall bias. The sampling frame was only from three slums selected from three different districts of Delhi, which might not be representative of entire urban poor population. In addition, due to time limitation, the data on demand side barrier was not collected extensively.

A sustained and focused IEC campaign to improve the awareness amongst community on $\mathrm{RCH}$ will help in improving community participation leading to sustaining and improving the quality, accessibility, and utilization of reproductive and child health services provided by the government agencies. There is a need to increase availability and accessibility of medical facilities in and around slums as the government facilities are poor. In absence of this, the slum dwellers have to visit private doctors or unqualified quacks for consultation and medicines. Municipal Corporation of Delhi should provide adequate dispensaries in various slum pockets to increase its accessibility. Further research on this aspect in the urban Indian context is required to understand the demand side barriers in utilization of $\mathrm{RCH}$ services which can help in identifying and suggesting the measures for improvement of the health care services especially the $\mathrm{RCH}$ services.

\section{DECLARATIONS \\ Financial support and sponsorship: Nil.}

Conflict of Interest: None of the authors of this paper have financial or non-financial competing interests with regards to the content of this paper.

\section{Ethics Approval}

Written informed consent was obtained from all the study participants and ethical approval was granted by The National Institute of Health and Family Welfare, New Delhi.

\section{Authors' Contributions}

Dr. Anand Kumar Verma contributed to the study concept, study design, conduct of the study and preparation of the manuscript. Dr. Rabi Bhushan contributed to the collection and interpretation of the data and preparation of the manuscript. Dr. Prakash Ranjan conducted statistical analysis and preparation of the manuscript. Dr. V. K. contributed to the overall concept and conduct of the study.

\section{REFERENCE}

1. Reproductive, maternal, newborn, child and adolescent health. https://mohfw.gov.in/sites/default/files/566589545 5663325.pdf. Accessed on - 12/10/2019

2. Child Health Program in India Major milestones in Child Health. https://mohfw.gov.in/2156472494RTI\%20Act\%2 C\%202005\%20for\%20Child\%20. Accessed on $14 / 10 / 2019$

3. Antenatal care (NICE clinical guideline 62). https://www.rcog.org.uk/en/guidelines-researchservices/guidelines/antenatal-care.Accessed on 24/12/2019

4. Sahoo M, Som M, Pradhan J. Perceived Barriers in Accessing the Reproductive Health Care Services in Odisha. Indian J Community Health. 2017;29(3):229-238. Accessed on 5/11/2019

5. RMNCH+A Government of India National Health Mission, Mini-- www.nhm.gov.in/nrhmcomponents/rmnch-a.html. Accessed on 27/1/2019

6. Devasenapathy N, Jerath SG, Allen E, Sharma S, Shankar AH, Zodpey S. Reproductive healthcare utilization in urban poor settlements of Delhi: Baseline survey of ANCHUL (Ante Natal and Child Health care in Urban Slums) project. BMC pregnancy and childbirth. 2015 Dec 1;15(1):212.

7. Uldbjerg CS, Schramm S, Kaducu FO, Ovuga E, Sodemann M. Perceived barriers to utilization of antenatal care services in northern Uganda: A qualitative study. Sex Reprod Healthc. 2020 Mar; 23:100464. doi: 10.1016/j.srhc.2019.100464. Epub 2019 Oct 25. PMID: 31710878. Accessed on $17 / 6 / 2019$

8. Chimatiro CS, Hajison P, Chipeta E, Muula AS. Understanding barriers preventing pregnant 
women from starting antenatal clinic in the first trimester of pregnancy in Ntcheu District-Malawi. Reproductive health. 2018 Dec 1;15(1):158.

9. Pahwa P, Aditya S. Existing practices and barriers to access of $\mathrm{MCH}$ services-a case study of residential urban slums of district Mohali, Punjab, India. Global journal of medicine and public health. 2013;2(4):1-8.

10. Singh V, Srivastava DK, Jain PK, Kumar S, Shukla SK, Singh N, Baranwal H. A cross sectional study to determine the reasons for nonutilization of reproductive and child health services in district Etawah. International Journal of Community Medicine and Public Health. 2020 Mar;7(3):1178.

11. Wendt A, Stephenson R, Young M, Webb-Girard A, Hogue C, Ramakrishnan U, Martorell R. Individual and facility-level determinants of iron and folic acid receipt and adequate consumption among pregnant women in rural Bihar, India. PloS one. 2015 Mar 20;10(3):e0120404.

12. Siekmans K, Roche M, Kung'u JK, Desrochers RE, De- Regil LM. Barriers and enablers for iron folic acid (IFA) supplementation in pregnant women. Maternal \& Child Nutrition. 2018 Dec;14:e12532.

13. Awosan K, Hassan M. Perception and Utilization of Tetanus Toxoid Immunization Among Pregnant Women Attending a Tertiary Centre in NorthWest Nigeria. JDDT. 2018, 8, 119-124 Accessed on $18 / 8 / 2019$

14. Wilunda C, Scanagatta C, Putoto G, Takahashi R, Montalbetti F, Segafredo G. Barriers to Institutional Childbirth in Rumbek North County, South Sudan: a Qualitative Study. Plos One. 2016;11(12):e0168083.

doi:10.1371/journal.pone.0168083 Accessed on 2/1/2019

15. Tarekegn SM, Lieberman LS, Giedraitis V. Determinants of maternal health service utilization in Ethiopia: analysis of the 2011 Ethiopian Demographic and Health Survey. BMC Pregnancy Childbirth. 2014; 14:161. Published 2014 May 7. doi:10.1186/1471-2393-14-161 Accessed on 27/1/2019. 